\title{
A HEGEMONIA DA HORTICULTURA DO MUNICÍPIO DE AMÉLIA RODRIGUES - BA: um relato da agricultura familiar local
}

\author{
THE HEGEMONY OF HORTICULTURE OF AMÉLIA \\ RODRIGUES - BA: A report on local family farming
}

\author{
Gabrielle Moreira Coutinho Cardoso ${ }^{1}$ \\ Bacharelanda em Geografia \\ Universidade Estadual de Feira de Santana \\ gabrielle-191@hotmail.com \\ Ákila Soares de Britto ${ }^{2}$ \\ Bacharelando em Geografia \\ Universidade Estadual de Feira de Santana \\ akilasbritto@hotmail.com
}

\section{Resumo}

Alguns dos produtos agrícolas comercializados nas feiras livres do município de Feira de Santana não são produzidos nele. Partindo desta reflexão buscou-se compreender a gênese destes produtos. A oportunidade de realizar uma atividade de observação e produção textual dentro da disciplina Geografia Rural I tem proporcionado à construção de uma investigação acerca da produção de hortaliças, o transporte e sua comercialização, sendo o município de Amélia Rodrigues o maior fornecedor.

Palavras - Chave: Horticultura. Agricultura familiar. Campesinato. Amélia Rodrigues

\begin{abstract}
Some of the agricultural products marketed in the free fairs of the municipality of Feira de Santana are not produced in it. From this reflection we sought to understand the genesis of these products. The opportunity to carry out an activity of observation and textual production within the discipline of Rural Geography I has provided the construction of an investigation about the production of vegetables, transportation and its commercialization, the municipality of Amélia Rodrigues is the largest supplier.
\end{abstract}

Keywords: Horticulture. Family farming. Peasantry. Amélia Rodrigues

\section{Introdução}

O presente relatório apresenta uma discussão e analise da agricultura familiar no município de Amélia Rodrigues (Mapa 1), que está localizado no norte do Recôncavo Baiano e constituinte da Região Metropolitana de Feira de Santana, no estado da Bahia. O foco da abordagem está relacionado a horticultura, surgindo assim uma reflexão sobre este modo de produção, tendo como referência dados estatísticos coletados no Censo 
A hegemonia da horticultura do município de Amélia Rodrigues - BA: um relato da agricultura familiar local
Gabrielle Moreira Coutinho Cardoso Ákila Soares de Britto

Agropecuário nos anos de 1995 e 2006 e observações cotidianas e relatos de feiras livres no município de Feira de Santana e visitas de campo no município de Amélia Rodrigues.

Deste modo identificamos como está inserida a agricultura familiar no município, quem são os agentes envolvidos nessa produção e qual a sua importância socioeconômica para a localidade.

É importante destacar que o município é beneficiado pela sua localização nos limites municipais com Conceição de Jacuípe, pioneiro nesse tipo de produção, sendo destaque pelo seu cinturão verde de horticultura, caracterizando-se como um polo distribuidor da região.

\section{Mapa 1 - Localização do município de Amélia Rodrigues - 2018}

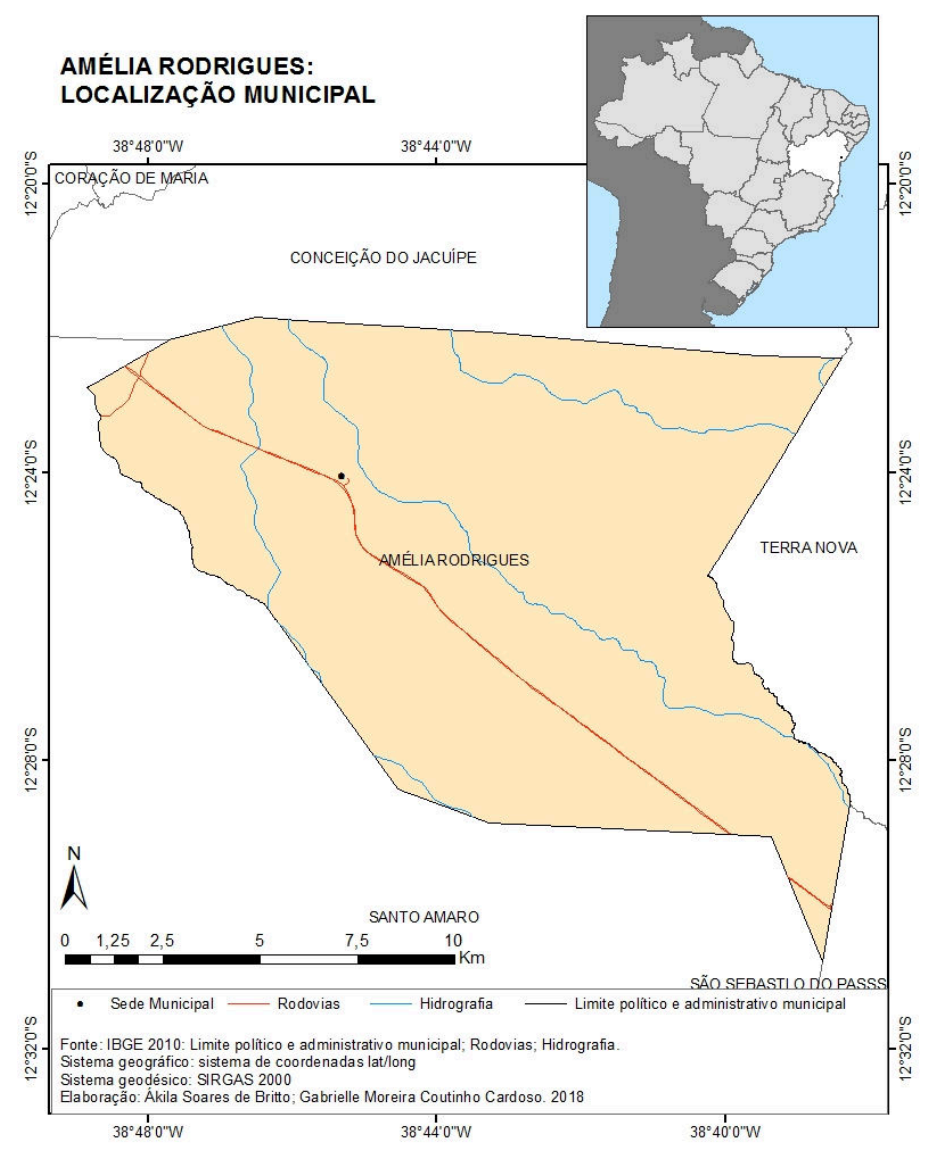

As hortaliças produzidas em Amélia Rodrigues seguem a mesma dinâmica, sendo distribuídas para vários centros comerciais como feiras, mercados e supermercados dos municípios vizinhos, trazendo aspectos positivos para a região, consequentemente aquecendo a economia local e aquecendo o modelo do capitalismo inserido no campo. 

Ákila Soares de Britto

É de saber comum a existência de diversos trabalhos voltados para Agricultura familiar, porém não existe nenhum relato específico sobre o modelo de horticultura em pequenos municípios. Deste modo, pretende-se ampliar as discussões voltadas à horticultura e agricultura familiar em pequenos municípios.

Trazemos também para a população e gestão local uma ampliação dos conhecimentos do ambiente em que vive, e proporciona respostas a perguntas frequentes e auxilia na geração de programas de apoio e incentivo a horticultura dentro da agricultura familiar.

\section{Horticultura na agricultura familiar: Surgimento da Agricultura Familiar}

Para fundamentar as discussões trazidas neste relato de campo, apresentamos elementos contextualizadores como um breve histórico da agricultura familiar, que possibilitou assim a caracterização das atividades exercidas em Amélia Rodrigues como pertencentes do modelo familiar.

O cultivo familiar é um modelo de agricultura, que por volta da década de 1990, era vista como pequenas produções de baixa renda, voltada a uma plantação de subsistência, ou seja, não havia o envolvimento do capital, ela era realizada por camponeses, que desenvolviam a relação de troca de mercadorias. A expressão da agricultura familiar, segundo Navarro (2014), começou a ser utilizada no Brasil na primeira metade dos anos 90 do século XX. Antes dessa nomenclatura, era utilizado os termos mini fundiários, pequenos produtores, agricultores de subsistência ou, como era corriqueiro na década de 1970, agricultores de baixa renda.

Os camponeses foram uma nomenclatura também utilizada para a denominação desses produtores, principalmente nas pesquisas sociais. A agricultura de um modo geral passou por grandes transformações ao logo dos anos, um fato marcante se deu a partir da Segunda Guerra Mundial, por uma série de transformações decorrentes do processo de modernização, conhecida como Revolução Verde. A inserção de máquinas, insumos e técnicas produtivas permitiram um grande aumento na produtividade da terra.

Com essas transformações, a agricultura familiar também se modificou. Surgiram assim novos costumes da vida no campo, onde o camponês insere o processo de capitalismo no campo, ou seja, o interesse da terra deixa de ser apenas de produção de subsistência e passa a ser um suporte produtivo da sociedade em geral. Atualmente 
no Brasil, a agricultura familiar é o setor responsável pela maioria das ofertas de produtos que alimentam a sociedade, desempenha uma performance indispensável para o segmento econômico e social do Brasil. Ainda que muito dispersa, a agricultura família do país corresponde por uma expressiva porção da produção agropecuária, devido ao grande contingente de estabelecimentos existentes.

É importante destacar que tem modelo com suas raízes no campesinato, principalmente em sua forma social. Com grande destaque nas relações propriedade, trabalho e família. Um dos fatores sociais em destaque está relacionado com a colaboração com a diminuição do êxodo rural e o aumento dos recursos das famílias envolvidas na produção.

Em termos gerais, o agricultor familiar segundo a Constituição brasileira, na Lei $\mathrm{n}^{\mathrm{o}} 11.326$ de julho de 2006, consiste aquele que desenvolve atividades econômicas no meio rural e que atende alguns requisitos básicos, tais como: não possuir propriedade rural maior que 4 módulos fiscais; utilizar predominantemente mão de obra da própria família nas atividades econômicas de propriedade; e possuir a maior parte da renda familiar proveniente das atividades agropecuárias desenvolvidas no estabelecimento rural.

\section{Horticultura na agricultura familiar: Breve discussão}

Deste modo podemos perceber que a agricultura familiar é sempre lembrada por sua importância na geração de emprego e na produção de alimentos. Estima-se que esse modelo está responsável pelo abastecimento do mercado interno com alimentos que são fornecidos a população brasileira. Além da produção voltada para o autoconsumo, ou seja, uma produção onde o modo de produção capitalista não está inserido, caracteriza uma menor produtividade e sem a utilização de utensílios tecnológicos na sua produção, sendo assim um modelo de campesinato. É claro que nem toda agricultura familiar é campesinato, porém todo campesinato é agricultura familiar, por conta das relações não capitalista de produção.

É importante destacar que a produção familiar é uma fonte de recursos para as famílias com menor renda, além de gerar riquezas, sendo um aspecto positivo ao município onde é desenvolvida o cultivo, sendo uma cadeia produtiva extensa, com vários agentes envolvidos, contribuindo assim para a sociedade de forma direta e indireta. Como 
parte da produção familiar a horticultura é uma ferramenta acessível por conta da grande variedade de produtos e períodos de produção.

Conforme a EMBRAPA, (2018) as hortaliças são plantas geralmente de ciclo curto e tratos culturais intensivos, e são utilizadas na alimentação humana. Fornecem folhas, hastes, flores, frutos, raízes. A produção de hortaliças pode estar inserida dentro de uma relação comercial ou de subsistência, possuindo um papel fundamental no que se refere a atividade agrícola familiar, colaborando para o seu crescimento e assegurando a sustentabilidade dos agentes envolvidos.

As hortaliças destacam-se por possibilitar um retorno econômico rápido, dando assim suporte a outras explorações com retorno de médio e longo prazo. Sendo uma cultura que se adapta à produção em pequenas áreas ou mesmo em sistema de consorciação com outras lavouras, além de requerer um baixo nível de investimento para se iniciar na atividade. A comercialização direta de hortaliças é a melhor alternativa para geração de lucro para os produtores. Com a maior procura por esses produtos a comercialização não pode ser restrita apenas para as feiras livres locais, para atingir a demanda de uma nova população e seus costumes é preciso ampliar o raio da cadeia produtiva em uma escala intermunicipal, expandindo os seus produtos para grandes centros comerciais.

\section{A agricultura familiar no município de Amélia Rodrigues}

Visualizamos na experiência de campo que as atividades agrícolas no município de Amélia Rodrigue destacam-se por características históricas, desde sua origem como um grande produtor de cana-de-açúcar, até os dias atuais com o crescente número de lavouras - permanentes ou temporárias - e a horticultura.

Para compreender a dinâmica de produção local, efetuamos a análise de dados coletados no IBGE (2006) referentes ao número de estabelecimentos familiares e não familiares (Tabela 1), com o intuito de comparar o perfil produtivo local. 
A hegemonia da horticultura do município de Amélia Rodrigues - BA: um relato da agricultura familiar local
Gabrielle Moreira Coutinho Cardoso Ákila Soares de Britto

Tabela 1 - Amélia Rodrigues: Número de estabelecimentos agropecuários por tipo de receita e agricultura familiar (Unidades) - 2006

\begin{tabular}{c|c|c|c|c|c|c}
\hline & \multicolumn{6}{|c}{ Tipo de receita } \\
\cline { 2 - 7 } $\begin{array}{c}\text { Agricultura } \\
\text { familiar }\end{array}$ & Total & $\begin{array}{c}\text { Produtos } \\
\text { vegetais }\end{array}$ & $\begin{array}{c}\text { Animais e } \\
\text { seus } \\
\text { produtos }\end{array}$ & Esterco & $\begin{array}{c}\text { Produtos da } \\
\text { agroindústria }\end{array}$ & $\begin{array}{c}\text { Prestação de } \\
\text { serviço para } \\
\text { empresas } \\
\text { integradoras }\end{array}$ \\
\hline $\begin{array}{c}\text { Não familiar } \\
\text { Agricultura } \\
\text { familiar }\end{array}$ & 68 & 53 & 30 & 3 & - & 1 \\
\hline
\end{tabular}

Fonte: IBGE - Censo Agropecuário, 2009.

Pode-se observar que o número de estabelecimentos familiares no município de um modo geral é quase cinco vezes maior que a quantidade de estabelecimentos não familiares, com um destaque na produção de vegetais que representa um total de $\sim 91 \%$ do valor total dos estabelecimentos familiares.

As informações permitiram juntamente com as observações de campo especular que o perfil municipal para os próximos anos deve se manter ligado a agricultura familiar voltada a produção de vegetais, motivada pela influência das características dos municípios vizinhos, grandes produtores vegetais - cinturão verde.

Fomos capazes também notar em campo que a agricultura familiar está inserida em outros tipos de observações, como é possível validar nos dados posteriormente coletados, a produção de animais, produtos agroindustriais e dentre outros, também estão inseridos nesse modelo de produção, fortalecendo a economia das famílias envolvidas.

Partindo dessa análise da produção de vegetais observamos a distribuição das atividades econômicas (Tabela 2) dentro da agricultura familiar:

Tabela 2 - Amélia Rodrigues: estabelecimentos agropecuários, com agricultura familiar e não familiar, por grupos de atividade econômica - 2006

\begin{tabular}{l|c|c|c|c}
\hline \multicolumn{4}{c}{ Variável - Número de estabelecimentos agropecuários (Unidades) } \\
\hline \multirow{4}{*}{ Agricultura familiar } & \multicolumn{4}{c}{ Grupos de atividade econômica } \\
\cline { 2 - 5 } & $\begin{array}{c}\text { Lavoura } \\
\text { temporária }\end{array}$ & $\begin{array}{c}\text { Horticultura e } \\
\text { floricultura }\end{array}$ & $\begin{array}{c}\text { Lavoura } \\
\text { permanente }\end{array}$ & $\begin{array}{c}\text { Pecuária e criação } \\
\text { de outros animais }\end{array}$ \\
\hline $\begin{array}{l}\text { Agricultura não familiar } \\
\text { Agricultura familiar }\end{array}$ & 23 & 7 & 0 & 16 \\
Lei 11.326 & 46 & 236 & 6 & 3 \\
\hline
\end{tabular}

Fonte: IBGE - Censo Agropecuário, 2009.

Analisando a tabela 2 vemos que no ano de 2006 a quantidade de estabelecimentos na agricultura familiar ligados a horticultura representaram $\sim 83.4 \%$ dos estabelecimentos 
com produção vegetal no município, enfatizando a hegemonia da horticultura na economia local quando se refere a agricultura, a produção vegetal em Amélia Rodrigues possui as vantagens de se encontrar entres as áreas das regiões metropolitanas de Feira de Santana e de Salvador, sendo estes municípios os principais consumidores da produção local.

No intuito de facilitar a visualização da importância da produção de hortaliças para a econômica local, observamos assim PIB municipal, para isso coletamos dados de 2006 a 2015 (Tabela 3), onde são classificados em três setores que são: agropecuária, indústria e serviços.

É notório que, a cidade vem evoluindo a cada ano, principalmente o setor agropecuário, deste modo destacando-se dentro da economia local quando cresce de forma linear até o ano de 2011, porém sofreu uma queda nos anos de 2012 e 2013, mas volta a crescer forte nos anos seguintes. (Gráfico 1)

Tabela 3 - Amélia Rodrigues: PIB por atividade econômica nos anos de

\begin{tabular}{c|c|c|c}
\multicolumn{4}{c}{$2006-2015$} \\
\hline \multirow{2}{*}{ ANO } & ATIVIDADE ECONÔMICA X VALOR DO PIB (X1.000) R\$ \\
\cline { 2 - 4 } & AGROPECUÁRIA & INDÚSTRIA & SERVIÇO \\
\hline 2006 & $11.915,00$ & $12.785,00$ & $34.546,00$ \\
2007 & $13.965,00$ & $11.265,00$ & $40.947,00$ \\
2008 & $14.628,00$ & $15.153,00$ & $51.652,00$ \\
2009 & $16.908,00$ & $25.556,00$ & $57.936,00$ \\
2010 & $18.250,00$ & $19.846,00$ & $56.635,00$ \\
2011 & $18.187,00$ & $26.287,00$ & $70.639,00$ \\
2012 & $15.630,00$ & $32.856,00$ & $79.071,00$ \\
2013 & $13.975,00$ & $39.688,00$ & $93.599,00$ \\
2014 & $28.195,00$ & $28.729,00$ & $114.631,00$ \\
2015 & $27.120,00$ & $23.663,00$ & $113.997,00$ \\
\hline
\end{tabular}

Fonte: IBGE, em parceria com os Órgãos Estaduais de Estatística, Secretarias Estaduais de Governo e Superintendência da Zona Franca de Manaus - SUFRAM, 2010.

${ }^{1}$ Exclusive Administração, defesa, educação e saúde públicas e seguridade social. 
Gráfico 1 - Amélia Rodrigues: Crescimento do PIB nos anos de 2006 - 2015

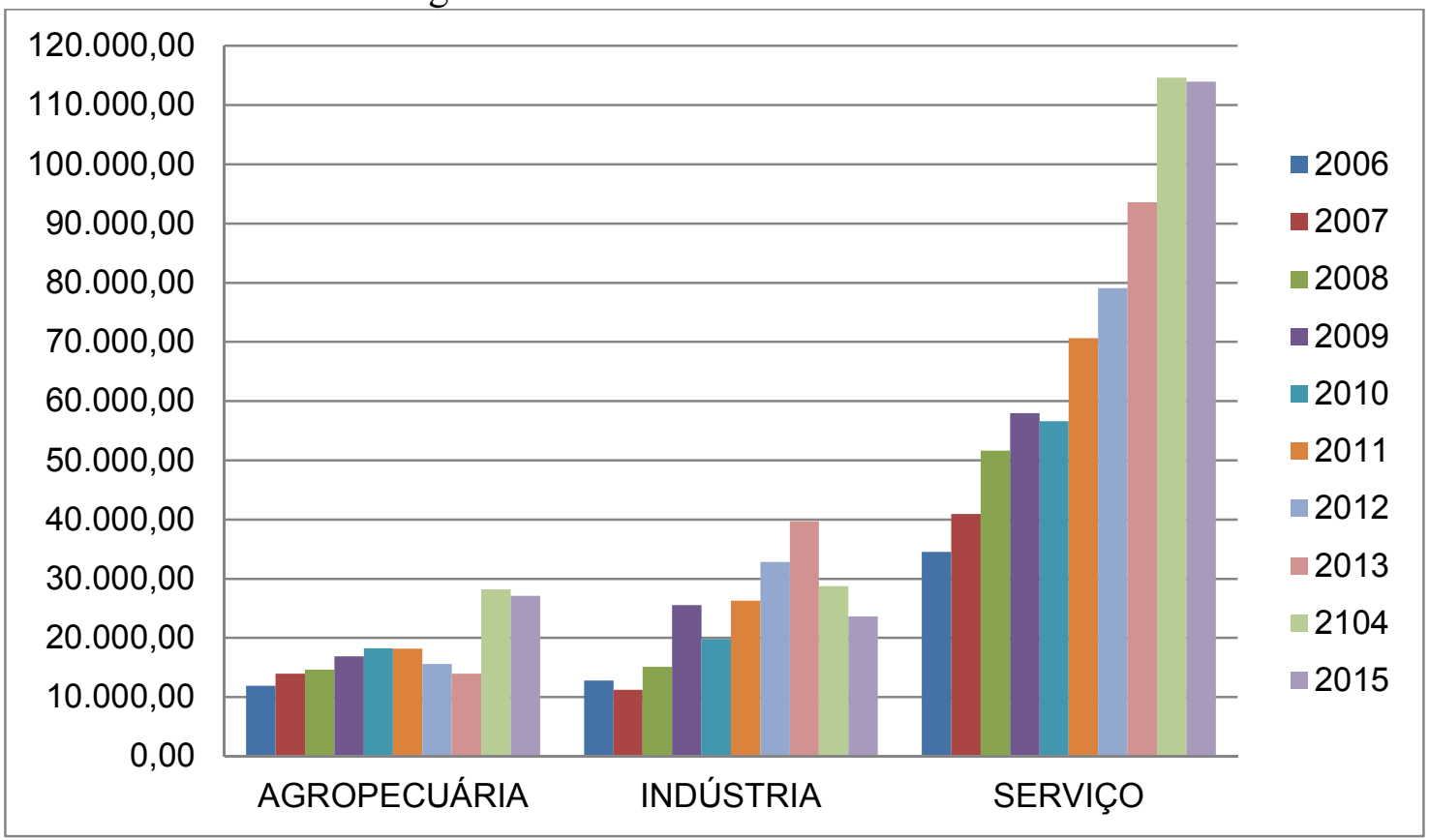

Elaboração dos autores com base na tabela 3 .

Esta queda nos anos de 2012 e 2013 estão diretamente relacionadas com o aumento do PIB industrial no mesmo período, isso decorre do processo de industrialização no município, aliado a fatores climáticos como: chuvas em excesso e secas prolongadas, fazendo com que muitos dos jovens deixem de executar a atividade agrária e dirijam-se para a área urbana em busca de novas oportunidades de emprego nas industrias.

Com a proposta de incentivar a permanência do trabalhador no campo, a prefeitura municipal de Amélia Rodrigues no ano de 2017, divulga no site da cidade que assinou o termo de adesão ao SEMAF (Serviço Municipal de Apoio à Agricultura Familiar). Com o objetivo de promover a inclusão dos agricultores familiares da produção local. Além disso, os Técnicos da Bahiater (Superintendência Baiana de Assistência Técnica e Extensão Rural), vinculada à Secretaria de Desenvolvimento Rural (SDR), passaram informações aos agricultores sobre a regularização e emissão da DAP (Declaração de Aptidão ao Programa Nacional de Fortalecimento da Agricultura Familiar), que foi criado para contribuir no acesso dos produtores a políticas públicas e incentivar na qualificação profissional além de favorecer a inativa de credito como: o Programa Nacional de Fortalecimento da Agricultura Familiar (Pronaf), os programas de compras instrucionais, como o de Aquisição de Alimentos (PAA) e o de Alimentação Escolar (PNAE), a 
Assistência Técnica e Extensão Rural (ATER), o Programa Garantia Safra e o Seguro da Agricultura Familiar.

É importante destacar que, os incentivos de produção entre os agentes envolvidos na agricultura são de fundamental importância para o fortalecimento econômico e social do município.

\section{Considerações Finais}

Relatamos que a agricultura familiar no município possui um destaque na economia local e na questão social, pois auxilia na fonte de renda e emprego de muitas famílias que dependem do campo para a sua subsistência, sendo assim, a horticultura destaca-se como uma das principais atividades econômicas agrícolas exercidas no município.

Para a construção e manutenção do modelo produtivo em destaque, se faz necessário o apoio da gestão local para integrar programas municipais, estaduais e federais de apoio à agricultura familiar para dar a oportunidade aos produtores de adquirir insumos agrícolas, fortalecendo a produção.

O Programa Nacional para Agricultura Familiar - Pronaf é um dos responsáveis pelos financiamentos de créditos presente na produção local, servindo de apoio principalmente nas épocas de seca, momento pelo qual o produtor enfrenta maiores dificuldades.

Com base nas informações apresentadas das observações feitas em campo e auxiliadas por teorias agrárias, Podemos afirmar que o auxílio e os programas possibilitam que a produção de horticultura seja efetuada durante todo ano, com maior ou menor intensidade incluindo o período de seca. Constituindo assim, uma hegemonia da atividade economia observada em questão. 


\section{Referências}

AGROPECUÁRIO, IBGE Censo. Brasil, grandes regiões e Unidades da Federação. Rio de Janeiro: IBGE, 2009.

AMARO, Geovani B. et al. Recomendações técnicas para o cultivo de hortaliças em agricultura familiar. Embrapa Hortaliças-Circular Técnica (INFOTECA-E), 2007.

EMBRAPA, O CULTIVO DE HORTALIÇAS. Disponível em:

https://www.embrapa.br/busca-de-publicacoes/-/publicacao/749966/o-cultivo-dehortalicas. Data de acesso: 13 fev. 2018.

NAVARRO, Zander; PEDROSO, Maria Thereza Macedo. A agricultura familiar no Brasil: da promessa inicial aos impasses do presente. Revista Econômica do Nordeste, v. 45, n. 5, p. 7-20, 2014.

NUNES, Sidemar Presotto. O desenvolvimento da agricultura brasileira e mundial e a idéia de Desenvolvimento Rural. Boletim eletrônico, DESER-Departamento de Estudos Socioeconômicos Rurais, p. 1-15, 2007.

Wesz, V J.; Lovis I. C. Desenvolvimento e agroindústria familiar. Disponível em: http://www.sober.org.br/palestra/12/05P305.pdf. Data de acesso: 13 fev.2018. 